\title{
Report
}

\section{The International Medical Society of Paraplegia}

The Annual General Meeting was held in the Royal College of Surgeons of Edinburgh, in Edinburgh, Scotland, on the 4th September, 1985, with the President, Professor Alain Rossier in the Chair.

Professor Rossier was re-elected for a further two year period as President. Mr. Phillip Harris was re-elected as Editor of 'Paraplegia'. New Members of Council elected were: Brigadier A. S. Chahal (India), Dr. H. J. Gerner (Germany), Dr. R. W. Hussey (U.S.A.), and Dr. A. Ohry (Israel). Dr. Estin Comarr (U.S.A.), Dr. A. Jousse (Canada) and Dr. John Young (U.S.A.) were elected to Emeritus Membership.

New Corresponding Secretaries are: Dr. E. Iwatsubo, Spinal Injuries Centre, Iizuka Iguisu, Iizuka, Japan 820; and Dr. V. Forner, Almirante Cadarso-3, Valencia 5, Spain.

The Society Medal was awarded to Mr. Phillip Harris, Edinburgh, Scotland: a Founder Member of the Society, and Editor of 'Paraplegia'.

A posthumous Medal of the Society was awarded to the late Professor Marian Weiss, Konstancin, Poland: it was presented to Mr. Z. Z. Byszewjski, representative of the Embassy of the Polish People's Republic, for Professor Weiss' widow.

Fifty-nine new members of the Society were elected.

A Scientific Committee; and a Membership Committee were inaugurated.

Future Meetings:

1986. Oslo, Norway, June 26th-28th. Full information is available from Dr. H. Natvig, Department of Neurology, Rikshospitalet, University Hospital, N-0027 Oslo 1, Norway. Main subjects: (1) Urological problems

(2) Technical aids and orthosis

(3) Regeneration in the central nervous system

(4) Sport and exercise

1987. Spring (probably 13th-15th May). Stoke Mandeville Hospital, Aylesbury, Bucks, England. Main subjects:

(1) Economic implications of longevity in spinal injury patients (to include ventilatory dependent patients) 
(2) Autonomic nervous system and neuropharmacology

(3) Non-traumatic paraplegia

(4) Methods of assessing neurological evolution following spinal cord injury, including documentation

1988. Perth, Western Australia 8th-14th May.

Also, a Regional Meeting of the I.M.S.O.P. in Seoul, Korea, in October, 1988. Swiss Fund Fellowship: The Swiss Inter-development Fund of the I.M.S.O.P. have endowed two Fellowships of $£ 3,000$ each for the year 1986, to assist the training of two doctors from developing countries.

Membership Booklet. An up to date membership list is being printed and a copy will be sent to all members of the I.M.S.O.P. 